\title{
The Reliability and Validity of the Turkish Version of the Mental Fatigue Scale In Healthy Individuals
}

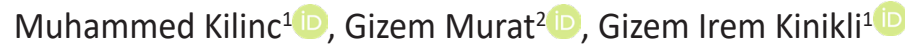 \\ ${ }^{1}$ Faculty of Physical Therapy and Rehabilitation, Hacettepe University, Ankara, Turkey. \\ ${ }^{2}$ Department of Physiotherapy and Rehabilitation, Faculty of Health Sciences, Mugla Sitki Kocman University, Mugla, Turkey \\ Correspondence Author: Gizem Murat \\ E-mail: gizemmurathu@gmail.com \\ Received: $07.04 .2020 \quad$ Accepted: 28.06.2021
}

\begin{abstract}
Objectives: The aim of the study was to investigate the reliability and validity of the Turkish version of the Mental Fatigue Scale (MFS) in healthy Turkish population.

Methods: This study was held in Hacettepe University, Faculty of Physical Therapy and Rehabilitation between April and August 2019. A total of one hundred thirty-two healthy participants aged between $18-50$ years were recruited. Reliability was investigated using test-retest reliability. The internal consistency of MFS was calculated using Cronbach's alpha coefficient. The validity of the MFS was assessed by comparing the MFS score with the 36-item Short Form Health Survey (SF-36) and Checklist Individual Strength Questionnaire (CIS-T) scores. Pearson correlation coefficient was used to evaluate validity.

Results: The test-retest reliability of the MFS were excellent in healthy Turkish population (ICC: 0.91 , with a $95 \%$ confidence interval of $0.88-$ 0.94). The scale had high internal consistency (Cronbach's $\alpha$ 0.86). For the validity, the correlations between the MFS and the total/subscales of CIS-T scores and SF-36 scores were good ( $p<0.001$ ). The correlations between the MFS and CIS-T subscales (subjective feeling of fatigue, $r=0.50$; concentration, $r=0.53$; motivation, $r=0.42)$ and CIS-T total $(r=0.56)$ were good $(p<0.001)$. Significant correlations were found between the MFS and SF-36 subscales (energy/fatigue, $r=0.54$; emotional well-being, $r=0.54$, general health, $r=0.41)(p<0.001)$.

Conclusion: The Turkish version of the Mental Fatigue Scale has been demonstrated to be valid and reliable to assess mental fatigue in Turkish population. The Turkish Mental Fatigue Scale is suggested to be a valuable tool for assessment of mental fatigue in healthy Turkish population.
\end{abstract}

Keywords: Mental fatigue, fatigue, reliability, validity, Turkish

\section{INTRODUCTION}

Fatigue is a common phenomenon in healthy persons and patients (1). Although there are many definitions of fatigue in the literature, there is a consensus that fatigue is a subjective, multidimensional and multifactorial phenomenon (2). Fatigue is defined as a decrease in the level of efficiency of the individual in terms of mental and physical activities, decrease in the capacity of physical and mental activity, or exhaustion and lack of energy separately from weakness or sadness due to working or other reasons $(3,4)$. Two main subheadings are often used to classify fatigue: - Physical and Mental fatigue. Mental fatigue is defined as a biopsychological condition characterized by tiredness and lack of energy during or after prolonged periods of cognitive activity (5).

According to the International Classification of Diseases, 10th revision (ICD-10) mental fatigue is included in the "mild cognitive disorder" or "neurasthenia" diagnostic groups, while in the Diagnostic and Statistical Manual of Mental Disorders, 4th edition (6), mental fatigue is contained in the "mild neurocognitive disorders" group. As a result of mental fatigue, various symptoms can be seen, namely subjective, behavioral and physiological. Subjectively, increased fatigue, decreased motivation and lack of energy; behaviorally, a decrease in performance during a cognitive task; physiologically, symptoms such as changes in brain activity can be cited as examples (5, 7-10). In addition, symptoms such as reduced concentration capacity, sensitivity to noise and light, irritability, stress sensitivity and sleep disturbance may also be seen (11). Mental fatigue is a widespread complaint in modern life. According to the study conducted in the Netherlands, half of working women and a third of men reported complaints about mental fatigue (5). In the United States survey conducted by Ricki et al., $38 \%$ of the working population reported fatigue (12). In addition, the rate of one year after a stroke fatigue was reported to be $70 \%(13,14)$.

Mental fatigue has a negative effect on many activities in our social or business life. According to the studies, it is stated that 
mental fatigue decreases the desire to continue the present activity, the level of commitment to the task at hand (15-17) and causes a decrease in cognitive and behavioral performance $(7,18,19)$. In order to understand the cause of mental fatigue, which is commonly seen today and causes many problems in daily life, it is important to evaluate the problem from a broad perspective. There are many scales and questionnaires evaluating fatigue in the literature (20-22).

Various generic and disease-specific fatigue rating scales are used to evaluate fatigue in patients. The Mental Fatigue Scale (MFS) developed by Johansson et al. specifically assesses mental fatigue (23). However, this scale has no Turkish adaptation with validity and reliability in healthy population. Therefore, the aim of this study was to investigate the Turkish translation of the Mental Fatigue Scale with its validity and reliability.

\section{METHODS}

\subsection{Participants}

This was a methodological, validity, and reliability study. A face-to-face interview was performed. It was planned that the sample size to be 10 times (140) the number of items in the scale $(24,25)$ and 140 people were participated in the study. A total of 132 healthy participants (out of 140) aged between 18-50 years were recruited between April and August 2019. Eight participants were excluded from the study because they had diabetes mellitus and used antidepressants. Participants who had psychiatric comorbidities (e.g. use of antidepressants, hypnotics, sedatives, or antipsychotics), cancer history, neurological diseases (e.g. Stroke) and diabetes mellitus were excluded from the study. Participants who met the inclusion criteria were informed about the study and volunteers were invited to participate in the study (Figure 1). Participants who agreed to participate in the study signed a written consent form before participating in the study. Ethical approval received from Hacettepe University Non-invasive Clinical Studies Ethical Board (Date:18.12.2018, Number: GO 18/1197-25).
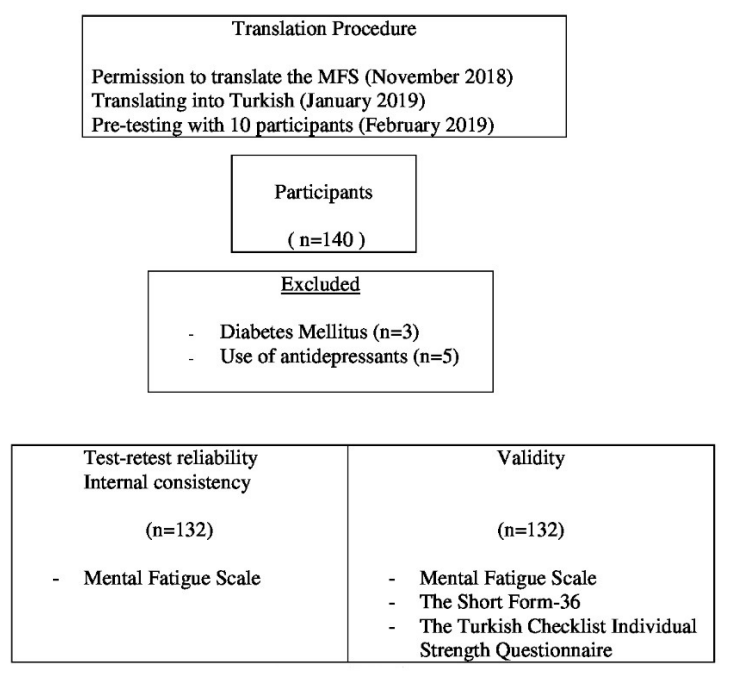

Figure 1. Study Design

\subsection{Translation Procedure}

The permission was obtained for the Mental Fatigue Scale from its developers (Lars Rönnbäck and Birgitta Johansson) and the translation procedures were followed according to a recommended procedure (23). Firstly, the original scale was translated from English into Turkish separately by two bilingual Turkish physiotherapists who have an advanced level of English. In order to create the first Turkish translation, both translations were compared by a bilingual person and the mismatches between the two translations were corrected. Then, the first Turkish translation was translated into English by two native speakers of English who know a good level of Turkish. The Turkish-to-English back-translation was then compared with the original scale. Following the completion of the translation procedure, pre-testing was conducted on 10 participants who met the inclusion criteria of the study to decide their comprehension of the Turkish version. The translated version was revised according to the difficulties of the participants in understanding the questions and the final Turkish version of MFS was decided.

A total of 132 participants filled the Turkish translation version of the MFS twice for test-re-test reliability assessment. The Turkish MFS was administered to all participants seven days later. To evaluate the validity of the MFS, the Short Form36 (SF-36) and the Turkish Checklist Individual Strength Questionnaire (CIS-T) were also completed by all participants during the first application of the MFS. We chose the CIS-T scale because there was no other Turkish scale evaluating mental fatigue parameters and the questions of the CIS-T scale were similar to the MFS scale questions. The reason for choosing SF-36 was that it contains mental fatigue subscale.

\subsection{Main Outcome Measurements}

\section{Mental Fatigue Scale (MFS)}

The Mental Fatigue Scale (MFS) is a 15-item questionnaire that specifically evaluates mental fatigue. It includes affective, cognitive and sensory symptoms, duration of sleep and daytime variation in symptom severity. The questions related to fatigue in general, lack of initiative, mental fatigue, mental recovery, concentration difficulties, memory problems, slowness of thinking, sensitivity to stress, increased tendency to become emotional, irritability, sensitivity to light and noise, decreased or increased sleep as well as 24-hour symptom variations. It has a 7-point Likert-type scale and is scored between 0 and 3 . A rating of 0 indicates normal function, 1 slight problem, 2 significant problems and 3 maximum problems. There are also items such as $0.5,1.5,2.5$ for marking when individuals fall between 2 items $(0.5,1.5$, 2.5). The total score of the scale is obtained by summing the scores of the first 14 questions. The last question is evaluated as yes or no. The scores range from 0 to 42 and 0-10 indicates no mental fatigue problem, 10.5-14.5 indicates slight mental fatigue, 15-20 indicates fairly serious mental fatigue, and $\geq$ 20.5 indicates serious mental fatigue (23). 


\section{Turkish Checklist Individual Strength Questionnaire (CIS-T)}

CIS is a scale of 20 questions used to assess various aspects of fatigue. The CIS evaluates 4 parameters of fatigue: (1) the subjective experience of fatigue (eight items); (2) reduction in motivation (four items); (3) reduction in activity (three items); and (4) reduction in concentration (five items). It has a 7-point Likert-type scale and is score between 1 and 7. A rating of 1 indicates 'Yes, that is true' and 7 indicates 'No, that is not true'. The total CIS score is calculated by summing the scores from four dimensions. Higher scores show a higher degree of fatigue, more concentration problems, lower motivation, and less activity (26). The validity and reliability of the Turkish version of CIS was made in 2011 by Ergin et al (27).

\section{Short-Form Health Survey (SF-36)}

The SF-36 was used to evaluate 8 dimensions of health. These eight dimensions include physical functioning, role limitations due to physical health, role limitations due to emotional problems, energy/fatigue, emotional well-being, social functioning, pain, general health. Gives a total score individually for each sub-dimension and points range from 0 to 100. A low score shows poor health status, while a high score shows good health status (28). The validity and reliability of the Turkish version was made in 1999 by Koçyiğit et al (29).

\subsection{Statistical Analysis}

All statistical analyses were completed using SPSS version 22.0 (SPSS Inc, Chicago, IL), with a level of significance of $5 \%$. Frequencies and descriptive statistics were used to calculate demographic variables. The measurement properties analyzed in this study for the instruments contained testretest reliability and validity. For all variables, test-retest reliability was determined by the intraclass correlation coefficient (ICC) using a one-way random model with under consistency. The minimum value recommended for this measurement property is 0.70 (Cronbach, 1951). Cronbach's alpha coefficient was used to estimate the internal consistency of MFS in our study, and a value of 0.70-0.9 was considered acceptable (30).

The validity of the MFS was assessed with analyzing the correlation between the SF-36 and CIS-T. The concurrent validity was determined using Pearson correlation analysis. The qualitative indicators for the relative ranges of correlation values were analyzed as follows: $: r \geq 0.81-1.0$ was excellent, $0.61-0.80$ was very good, $0.41-0.60$ was good, $0.21-0.40$ was fair, and $0.00-0.20$ was poor (31).

\section{RESULTS}

Demographic characteristics of the participants were shown in Table 1.
Table 1. Demographic characteristics $(n=132)$

\begin{tabular}{|c|c|}
\hline Age (year) $(X \pm S D)$ & $33.28 \pm 10.01$ \\
\hline \multicolumn{2}{|l|}{ Gender, n (\%) } \\
\hline Female & $88(66.7)$ \\
\hline Male & $44(33.3)$ \\
\hline \multicolumn{2}{|l|}{$\mathrm{BMI}(\mathrm{kg} / \mathrm{m} 2), \mathrm{n}(\%)$} \\
\hline Thinness & $11(8.3)$ \\
\hline Normal & $60(45.5)$ \\
\hline Overweight & $42(31.8)$ \\
\hline Obese Class I & $17(12.9)$ \\
\hline Obese Class II & $2(1.5)$ \\
\hline Obese Class III & $0(0)$ \\
\hline \multicolumn{2}{|l|}{ Marital Status, n (\%) } \\
\hline Single & $59(44.7)$ \\
\hline Married & $68(51.5)$ \\
\hline Divorced & $5(3.8)$ \\
\hline \multicolumn{2}{|l|}{ Education, n (\%) } \\
\hline Primary education & 15 (11.4) \\
\hline Secondary education & $21(15.9)$ \\
\hline University & $81(61.4)$ \\
\hline Postgraduate & $15(11.4)$ \\
\hline Working Hours (min.) $(X \pm S D)$ & $506.82 \pm 56.00$ \\
\hline Sleep Hours (min.) $(X \pm S D)$ & $433.64 \pm 79.62$ \\
\hline \multicolumn{2}{|l|}{ Social Activity, n (\%) } \\
\hline Yes & $32(24.2)$ \\
\hline No & $100(75.8)$ \\
\hline \multicolumn{2}{|l|}{ Sport Activity, n (\%) } \\
\hline Yes & $51(38.6)$ \\
\hline No & $81(61.4)$ \\
\hline Sport Activity Hours (min.) $(X \pm S D)$ & $236.18 \pm 97.25$ \\
\hline \multicolumn{2}{|l|}{ Smoke, n (\%) } \\
\hline Yes & $34(25.8)$ \\
\hline No & $98(74.2)$ \\
\hline
\end{tabular}

\subsection{Reliability of the MFS}

One-hundred and thirty-two participants were used to calculate test-retest reliability. The test-retest reliability, as assessed by the ICC, was 0.91 , with a $95 \%$ confidence interval of $0.88-0.94$, thus showing very high degree of reliability. Internal consistency was assessed using Cronbach's alpha and Cronbach's alpha was found 0.86 . Also, we calculated itemtotal score correlations for each item and these correlations were adequate ranged between 0.43 and 0.69 (Table 2). Thus, there was no need to remove any item.

\subsection{Validity of the MFS}

For the validity, the correlations between the MFS and the total/subscales of CIS-T scores and SF-36 scores were good $(p<0.001)$. The correlations between the MFS and CIS-T subscales (subjective feeling of fatigue, $r=0.50$; concentration, $r=0.53$; motivation, $r=0.42$ ) and CIS-T total $(r=0.56)$ were good $(p<0.001)$. Significant correlations were found between the MFS and SF-36 subscales (energy/fatigue, $r=0.54$; emotional well-being, $r=0.54$, general health, $r=0.41$ ) $(p<0.001)$. Fair correlations were found between the MFS 
and CIS-T (physical activity, $r=0.24$ ), SF-36 subscales (role limitations due to physical health, $r=0.26$; role limitations due to emotional problem, $r=0.32$; social functioning, $r=0.35$; pain, $r=0.35)(p<0.001)$. Poor correlation was found between the MFS and SF-36 subscale (physical functioning, $r=0.19$ ) $(p=0.005)$. All correlation coefficients for the comparisons described, including the comparison between the MFS and CIS-T and the SF-36 are demonstrated in Table 3.

Table 2. Corrected item-total correlation, item mean, and standard deviation for the MFS $(n=132)$

\begin{tabular}{|lllll|}
$\begin{array}{l}\text { Questions of } \\
\text { MFS }\end{array}$ & Mean & SD & $\begin{array}{c}\text { Item-total } \\
\text { correlation }\end{array}$ & $\begin{array}{c}\text { Cronbach's a } \\
\text { if item } \\
\text { deleted }\end{array}$ \\
\hline MFS-1 & 1.36 & 0.78 & 0.48 & 0.86 \\
\hline MFS-2 & 0.92 & 0.74 & 0.69 & 0.84 \\
\hline MFS-3 & 1.08 & 0.93 & 0.65 & 0.85 \\
\hline MFS-4 & 0.88 & 0.84 & 0.59 & 0.85 \\
\hline MFS-5 & 0.98 & 0.75 & 0.58 & 0.85 \\
\hline MFS-6 & 1.00 & 0.75 & 0.57 & 0.85 \\
\hline MFS-7 & 0.79 & 0.66 & 0.67 & 0.85 \\
\hline MFS-8 & 1.25 & 1.03 & 0.48 & 0.86 \\
\hline MFS-9 & 1.06 & 0.86 & 0.59 & 0.85 \\
\hline MFS-10 & 0.95 & 0.83 & 0.49 & 0.86 \\
\hline MFS-11 & 0.90 & 0.77 & 0.35 & 0.86 \\
\hline MFS-12 & 1.11 & 0.66 & 0.49 & 0.86 \\
\hline MFS-13 & 0.77 & 0.73 & 0.26 & 0.87 \\
\hline MFS-14 & 0.55 & 0.79 & 0.43 & 0.86 \\
\hline
\end{tabular}

MFS Mental Fatigue Scale, SD standard deviation

Table 3. Correlation between MFS with the other outcome measurements

\begin{tabular}{|c|c|c|c|}
\hline Outcome measurements & $\begin{array}{l}n=132 \\
\text { Mean }(X \pm S D)\end{array}$ & $r[95 \% \mathrm{Cl}]$ & $\mathbf{p}$ \\
\hline $\begin{array}{l}\text { CIS-T - Subjective feeling } \\
\text { of fatigue }\end{array}$ & $29.62 \pm 11.32$ & $0.50[0.32-0.66]$ & 0.001 \\
\hline CIS-T - Concentration & $16.78 \pm 7.57$ & $0.53[0.39-0.65]$ & 0.001 \\
\hline CIS-T - Motivation & $12.73 \pm 5.20$ & $0.42[0.23-0.57]$ & 0.001 \\
\hline CIS-T - Physical activity & $9.11 \pm 4.45$ & $0.24[0.08-0.40]$ & 0.001 \\
\hline CIS-T - Total & $68.23 \pm 23.06$ & $0.56[0.39-0.69]$ & 0.001 \\
\hline $\begin{array}{l}\text { SF-36-Physical } \\
\text { functioning }\end{array}$ & $81.68 \pm 19.83$ & $-0.19[-0.38-0.00]$ & 0.005 \\
\hline $\begin{array}{l}\text { SF-36-Role limitations } \\
\text { due to physical health }\end{array}$ & $76.51 \pm 35.45$ & $-0.26[-0.42-(-0.09)]$ & 0.001 \\
\hline $\begin{array}{l}\text { SF- } 36 \text { - Role limitations } \\
\text { due to emotional } \\
\text { problems }\end{array}$ & $62.62 \pm 41.40$ & $-0.32[-0.50-(-0.14)]$ & 0.001 \\
\hline SF-36 - Energy/fatigue & $55.83 \pm 20.18$ & $-0.54[-0.67-(-0.40)]$ & 0.001 \\
\hline $\begin{array}{l}\text { SF-36 - Emotional well- } \\
\text { being }\end{array}$ & $68.51 \pm 15.94$ & $-0.54[-0.66-(-0.41)]$ & 0.001 \\
\hline SF-36 - Social functioning & $71.02 \pm 24.09$ & $-0.35[-0.52-(-0.17)]$ & 0.001 \\
\hline SF-36-Pain & $77.51 \pm 20.33$ & $-0.35[-0.53-(-0.16)]$ & 0.001 \\
\hline SF-36-General health & $63.44 \pm 17.80$ & $-0.41[-0.57-(-0.24)]$ & 0.001 \\
\hline
\end{tabular}

\section{DISCUSSION}

Turkish adaptation of the Mental Fatigue Scale (MFS) was performed and psychometric properties were examined in the present study. The results demonstrated that the Turkish version of the MFS is valid and reliable. Although mental fatigue affects all populations today, there are insufficiencies in detecting its presence and determining its severity. The Mental Fatigue Scale developed to measure mental fatigue has proven validity and reliability in neurological patients (23).

Reliability is defined as a measure of invariance with respect to time or to obtain similar results if a measurement process is repeated (32). The internal consistency level of the scale was found to be high (Cronbach's $\alpha=0.86$ ) in the present study. All the corrected item-total correlations were adequate. The internal consistency findings of our study are consistent with the original version (Cronbach's $\alpha=0.94$ ) and the Chinese version (Cronbach's $\alpha=0.92$ ) of the MFS $(23,33)$.

The test-retest method is another method used to determine the reliability coefficient based on the fact that a test is applied twice to the same individuals under the same conditions and at a given time interval (32). In our study, the test-retest test was applied at 7-day intervals and the ICC value was found to be 0.91 . The test-retest was also found to be high. These results are very similar to other language version of the MFS (Chinese version of the MFS scale), (ICC: 0.97) (33). This finding suggest that the MFS is reliable measure in Turkish language.

Validity is a concept that indicates how accurately a method measures what it is intended to measure (32). In this study, SF-36 and CIS-T scales were used to test validity. In the Chinese version of the MFS scale, the validity of the scale was tested with 'Chalder Fatigue Scale (CFS)' and 'The Clinically Useful Depression Outcome Scale (CUDOS)'. There was a very good correlation between MFS and CUDOS. There was a good correlation between physical fatigue dimension and MFS, which is one of the two subscales of the CFS scale, and a very good correlation was found between mental fatigue dimension (33).

Similarly, in present study, the correlations of the MFS with the subjective feeling of fatigue, concentration and motivation subscales of the CIS-T were good. These results suggest that the MFS includes motivation, concentration and fatigue parameters. Also, a good correlation was found between emotional well-being and energy/fatigue subscales of the SF-36. Therefore, the MFS scale also support the quality of life aspects. On the other hand, the relationship between physical activity, which is the subscales of CIS-T scale related to physical fatigue, and MFS scale was found to be fair in the present study. In addition to this, the relationship between SF-36 sub-parameters related to physical functions and MFS scale was poor. As the MFS scale is a mental fatigue specific measurement, these results are not surprising.

The present study had some limitations. The major limitation is that there are no other language versions (except Chinese 
version) of the MFS to compare our results. Secondly, our participants did not show a homogeneous distribution in terms of gender and age. Our study is a single-centered study, and therefore, all the participants were from the same region (Ankara). These factors may limit the generalizability of the results.

Moreover, determining the type of fatigue or determining the contribution of mental fatigue to total fatigue has a key role in the fight against fatigue and appropriate treatment planning. In this respect, the fact that the first mental fatigue scale, which was shown to be valid and reliable in Turkish, could be used in this group of patients increases the importance of our study. Fatigue is also an important problem that should not be overlooked in people with neurological diseases. It is one of the most important problems of patients, especially in patients with stroke, multiple sclerosis and traumatic brain injury. In further studies, this scale is recommended to be used in neurological patients.

\section{Conclusions}

The results of the present study demonstrated that the MFS has good measurement properties to quantify mental fatigue in Turkish population. The Turkish Mental Fatigue Scale is suggested to be a valuable tool for assessment of mental fatigue in healthy Turkish population.

\section{Acknowledgements}

The authors would like to thank the participants. The authors also would like to Sevilay KARAHAN, Assist., Prof., PhD. for her valuable support in biostatistical analysis. The authors also thank Lars Rönnbäck and Birgitta Johansson for their permissions to translate the MFS into Turkish.

\section{Conflict of interest}

The authors report that they have no conflicts of interest.

\section{REFERENCES}

[1] Pawlikowska T, Chalder T, Hirsch S, Wallace P, Wright D, Wessely S. Population based study of fatigue and psychological distress. BMJ 1994;308(6931):763-766.

[2] Başoğlu F, Öncü J, Kuran B, Alptekin HK. The reliability and validity of The Turkish version of Multidimensional Fatigue Inventory-20 for the evaluation of different dimensions of fatigue in patients with fibromyalgia. Turk J Phys Med Rehabil 2020, 66.4: 436.

[3] Aaronson LS, Teel CS, Cassmeyer V, Neuberger GB, Pallikkathayil L, Pierce J, Press AN, Williams PD, Wingate A. Defining and measuring fatigue. Image J Nurs Sch 1999;31(1):45-50.

[4] Lewis G, Wessely S. The epidemiology of fatigue: more questions than answers. J Epidemiol Community Health 1992;46(2):92.

[5] Boksem MA, Tops M. Neurocognitive Disorders. Mental fatigue: costs and benefits. Brain Res Rev 2008;59(1):125-139.
[6] Black DW, Grant JE. Diagnostic and statistical manual of mental disorders (DSM-5). USA: American Psychiatric Publishing; 2013.p.366-389

[7] Van der Linden D, Eling P. Mental fatigue disturbs local processing more than global processing. Psychol Res 2006;70(5):395-402.

[8] Boksem MA, Meijman TF, Lorist MM. Mental fatigue, motivation and action monitoring. Biol Psychol 2006;72(2):123-132.

[9] Krupp LB, Alvarez LA, LaRocca NG, Scheinberg LC. Fatigue in multiple sclerosis. Arch Neurol 1988;45(4):435-437.

[10] Matthews G, Desmond PA. Stress and driving performance: Implications for design and training. Desmond PA, Hancock PA, editors. Stress, workload, and fatigue. First Edition, USA: Lawrence Erlbaum Associates Publishers; 2001.p.211-231

[11] Wascher E, Rasch B, Sänger J, Hoffmann S, Schneider D, Rinkenauer G, Heuer $\mathrm{H}$, Gutberlet I. Frontal theta activity reflects distinct aspects of mental fatigue. Biol Psychol 2014;96:57-65.

[12] Ricci JA, Chee E, Lorandeau AL, Berger J. Fatigue in the US workforce: prevalence and implications for lost productive work time. J Occup Environ Med 2007;49(1):1-10.

[13] Carlsson G, Moller A, Blomstrand C. Consequences of mild stroke in persons $<75$ years-a 1-year follow-up. Cerebrovasc Dis 2004;11:279-280.

[14] Schepers VP, Visser-Meily AM, Ketelaar M, Lindeman E. Poststroke fatigue: course and its relation to personal and stroke-related factors. Arch Phys Med Rehabil 2006;87(2):184188.

[15] Hockey GRJ. Compensatory control in the regulation of human performance under stress and high workload: A cognitiveenergetical framework. Biol Psychol 1997;45(1-3):73-93.

[16] Holding DH. Fatigue. Hockey GRJ, editor. Stress and fatigue in human performance. USA: John Wiley \& Sons Inc; 1983.p.123144.

[17] Meijman TF. The theory of the stop-emotion: On the functionality of fatigue. Proceedings of the 2 nd International Conference on Ergonomics and Safety for Global Business Quality and Productivity; 2000; Poland; PP. 45-50.

[18] Lorist MM, Boksem MA, Ridderinkhof KR. Impaired cognitive control and reduced cingulate activity during mental fatigue. Brain Res Cogn Brain Res 2005;24(2):199-205.

[19] Boksem MA, Meijman TF, Lorist MM. Effects of mental fatigue on attention: an ERP study. Brain Res Cogn Brain Res 2005;25(1):107-116.

[20] Armutlu K, Keser I, Korkmaz N, Akbıyık Di, Sümbüloğlu V, Güney Z, Karabudak R. Psychometric study of Turkish version of Fatigue Impact Scale in multiple sclerosis patients. J Neurol Sci 2007; 255(1-2):64-68.

[21] Yildirim Y, Ergin G. A validity and reliability study of the Turkish Multidimensional Assessment of Fatigue (MAF) scale in chronic musculoskeletal physical therapy patients. J Back Musculoskelet Rehabil 2013;26(3):307-316.

[22] Armutlu K, Korkmaz NC, Keser I, Sumbuloglu V, Akbiyik DI, Guney Z, Karabudak R. The validity and reliability of the Fatigue Severity Scale in Turkish multiple sclerosis patients. Int J Rehabil Res 2007;30(1):81-85.

[23] Johansson B, Starmark A, Berglund P, Rödholm M, Rönnbäck L. A self-assessment questionnaire for mental fatigue and related symptoms after neurological disorders and injuries. Brain Inj 2010;24(1):2-12. 
[24] Tezbasaran, AA. A comparison of conventional item analysis techniques to construct Likert type scales. TPD. 2004;19:7788.

[25] Karakoç F, Dönmez L. Basic principles of scale development. Tıp Eğitimi Dünyası. 2014;40:39-49 (Turkish).

[26] Vercoulen JH, Swanink CM, Fennis JF, Galama JM, van der Meer JW, Bleijenberg G. Dimensional assessment of chronic fatigue syndrome. J Psychosom Res 1994;38(5):383-392.

[27] Ergin G, Yildirim Y. A validity and reliability study of the Turkish Checklist Individual Strength (CIS) questionnaire in musculoskeletal physical therapy patients. Physiother Theory Pract 2012;28(8):624-632.

[28] McHorney CA, Ware JE, Raczek AE. The MOS 36-Item ShortForm Health Survey (SF-36): II. Psychometric and clinical tests of validity in measuring physical and mental health constructs. Med Care 1993;31:247-263.
[29] Koçyiğit H, Aydemir Ö, Fişek G, Ölmez N, Memiş A. The validity and reliability of Turkish version of the Short Form 36 (SF-36). Turkish J Drugs Therap 1999;12:102-106 (Turkish).

[30] Streiner DL, Norman GR, Cairney J. Validity. Streiner DL, Norman GR, Cairney J, editors. Health measurement scales: a practical guide to their development and use. Oxford University Press, USA; 2015.p.227-250.

[31] Landis JR, Koch GG. The measurement of observer agreement for categorical data. Biometrics 1977:159-174.

[32] Alpar R. Geçerlik ve güvenirlik. Spor, sağlık ve eğitim bilimlerinden örneklerle uygulamalı istatistik ve geçerlikgüvenirlik: Ankara: Detay Yayıncılık; 2010.p.493-497 (Turkish).

[33] Chiu HY, Li W, Lin JH, Su YK, Lin EY, Tsai PS. Measurement properties of the Chinese version of the Mental Fatigue Scale for patients with traumatic brain injury. Brain Inj 2018;32(5):652-664.

How to cite this article: Kilinc M, Murat G, Kinikli GI. The Reliability and Validity of the Turkish Version of the Mental Fatigue Scale In Healthy Individuals. Clin Exp Health Sci 2021; 11: 381-386. DOI: 10.33808/ clinexphealthsci.715517 